\title{
Use of petrophysical data for siting of deep geological repository of radioactive waste
}

\author{
Liliana Petrenko ${ }^{1, *}$, and Vyacheslav Shestopalov ${ }^{1}$ \\ ${ }^{1}$ Institute of Geological Sciences of NAS of Ukraine, 01054 Kyiv, Ukraine
}

\begin{abstract}
The paper is devoted to analyzing the petrophysical properties and petrographical characteristics of Volyn region with the view to choosing the least permeable and so the most suitable geological formation for the radioactive waste disposal. On a basis of the petrophysical estimations of the granitoids properties the argumentation of permeability has been developed for the petrotypes of Volyn region. Also method of classification of the petrotypes with their relative rate of suitability for radioactive waste disposal was developed. As a result of studying the perspectives were shown of the zhytomyr and korosten types of the granitoids as host rock for the radioactive waste disposal. According to the results of investigations performed by Swedish researchers a comparative analysis of rocks based on the age of formation, composition, structural features and some petrophysical properties of granitoids as host rocks for repository of radioactive waste was performed. Detail comparison the data of the granitoids of the Forsmark site in Sweden and the data of the granitoids of the Volyn megablock can be one of the next steps in researching the host rocks for the development of the RW disposal system in Ukraine.
\end{abstract}

\section{Introduction}

In accordance with the international experience of radioactive waste management, geological repository designed for a long-term use, is the only technically feasible alternative to safe isolation of the most dangerous radioactive waste (RW). In such a system rocks play an important role.

According to the State Program [1] and the Strategy for Radioactive Waste Management [2], the geological repository of RW should be located within the Chornobyl Exclusion Zone (CEZ) or the adjacent areas. This approach provides the greatest safety for radioactive waste transfer to their place of disposal. Because of this, the role of the host geological environment for the disposal of radioactive waste is preferred by the granitoid formations of the Volyn megablock and its surroundings.

Assessment of the "internal" permeability as the permeability of rocks around the disposal facility, and not only the "transit" characteristic of the environment is an important

\footnotetext{
* Corresponding author: Petrenko.L@nas.gov.ua
} 
task for siting of safe geological repository of radioactive waste. The problem is that today most of the existing remote methods (seismic and other geophysical studies, as well as, in part, aerospace method) for direct determination of the filtration properties of deep-lying rocks in their natural occurrence are aimed at obtaining information on the relative permeability of the rock blocks, the bodies, and not of specific geological formation in the zone of waste packages disposal. Thus, the application of the above studies is not sufficiently complete.

Evaluation of permeability on the basis of analysis of petrophysical properties (density, porosity, thermal conductivity, etc.) and petrographic peculiarities will not allow us to directly determine the rock permeability, but only indirectly. It is equally important that the obtained results of the analysis of the petrophysical characteristics of granitoids for the Volyn megablock can be extrapolated to the CEZ rocks prior to the prospecting and exploration work stages. This will allow us to focus on more suitable areas.

Data for researches provided by the Problem Research Laboratory of Physical and Chemical Researches of Rocks of the Institute of Geology National Taras Shevchenko University of Kyiv.

\section{Results}

\subsection{The structure and texture features of the main complexes of the Volyn megablock}

According to Swedish System [3], the initial stage of siting the repository of radioactive waste is to select sites that are characterized by geological homogeneous composition and structure of rocks. One of the criteria for selecting a site at the stage of regional research is the following: the site should be located within the watershed areas, outside the rivers floodplains, out of the regional fault zones, within the areas of low density of local faults, within the areas of low gradient geophysical fields.

The Volyn megablock is located in the northwest part of the Ukrainian Shield (US). It is composed of the deposits of the sedimentary cover (formations of the Mesozoic and Cenozoic systems) and the Archaean-Proterozoic crystalline rocks of the basement. Weathering crust is of mosaic occurrence. The structure of the Volyn megablock includes seven complexes (Perzhanskyi, Korostenskyi, Kyshynskyi, Osnytskyi, Bukynskyi and Zhytomyr) and 35 key petrotypes. Petrotype must be understood as the geologically similar type, formed in specific and rather limited thermodynamic, physical and chemical conditions, characterized by comparable composition, structural and texture features and physical properties [4]. Below and thereafter the main attention is paid to the complexes and their petrotypes, which are most commonly developed in the CEZ. Zhytomyr complex is represented mainly by uniformly granular, occasionally porphyry-shaped granites with massive texture. In the anticlinal structures granites form separate stranded blocks of medium-grained uniformly granular muscovite-biotite granites up to $20 \mathrm{~km}^{2}$ in area (Zhytomyrskyi etc), small massifs of porphyry-shaped granites, as well as larger massifs of porphyry-shaped granites. The largest massifs - Korostyshivskyi, Kamianobrodskyi, Fedorivskyi, and Krasnogorskyi have the area of $100-300 \mathrm{~km}^{2}$. Granitoids of the Korostenskyi complex, together with the magmatites of basic (subsilicic) composition (gabbro, anorthosites) form the Korostenskyi (Korosten) Pluton. The petrotypes of the Korosten complex belong to the medium-and coarse-grained fraction of the massive texture, except for the Ignatpilskyi rapakivi-like granite, which is finely and mediumgrained. 


\subsection{Petrophysical characteristics of the main petrotypes of the Korostenskyi and Zhytomyr complexes}

The purpose of the petrophysical assessment is based on the separation of granitoids of the Volyn megablock into relatively more suitable and relatively less suitable ones in accordance with the requirements for rock formations when creating a waste disposal system. The physical properties of crystalline rocks, which characterize their minimal permeability, correspond most to the conditions of safe disposal of RW. They involve porosity and density. Thermal, magnetic and strength characteristics of rocks are closely related to them. These properties (see the average value of the petrophysical characteristics of the key petrotypes in Table 1), as well as rock composition, structural and textural features should be taken into account when substantiating the suitability of the petrotype as the host rock environment for creation of a RW disposal facility.

Table 1. The average value of the petrophysical characteristics of the key petrotypes of the Korostenskyi and Zhytomyr complexes.

\begin{tabular}{|c|c|c|c|c|c|c|c|c|}
\hline Petrotypes & 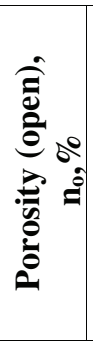 & 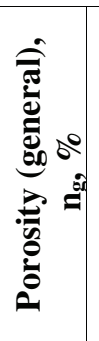 & 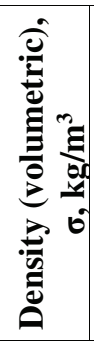 & 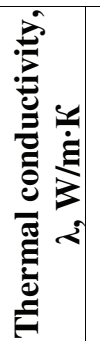 & 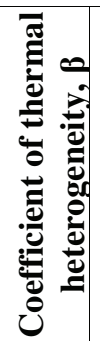 & 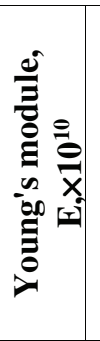 & 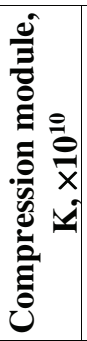 & 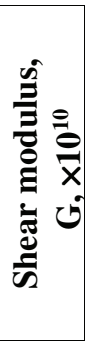 \\
\hline \multicolumn{9}{|c|}{ Korostensky complex } \\
\hline granite Liznikovsky & 0.59 & 1.79 & 2617 & 3.49 & 0.14 & 7.0 & 4.1 & 2.9 \\
\hline rapakivi-like granite Ignatpilsky & 0.12 & 1.14 & 2630 & 3.27 & 0.13 & 7.1 & 4.5 & 2.9 \\
\hline rapakivi-like granite Norinsky & 0.37 & 2.48 & 2595 & 2.80 & 0.17 & 6.5 & 4.5 & 2.6 \\
\hline rapakivi-like granite Rozsokhivsky & 0.37 & 1.15 & 2601 & 3.16 & 0.24 & 6.9 & 4.6 & 2.7 \\
\hline granite Berezovsky & 0.33 & 2.10 & 2612 & 3.39 & 0.22 & 7.1 & 4.5 & 2.9 \\
\hline rapakivi-like granite Emelyanovsky & 0.32 & 1.64 & 2621 & 3.11 & 0.31 & 6.0 & 3.5 & 2.5 \\
\hline rapakivi-like granite Korostensky & 0.40 & 1.73 & 2618 & 3.21 & 0.14 & 6.6 & 3.7 & 2.8 \\
\hline rapakivi-like granite Potyivsky & 0.26 & 2.18 & 2659 & 2.94 & 0.30 & 8.1 & 5.2 & 3.3 \\
\hline granite rapakivi- Malinsky & 0.31 & 1.66 & 2635 & 2.92 & 0.17 & 6.9 & 4.3 & 2.8 \\
\hline \multicolumn{9}{|c|}{ Zhytomyr complex } \\
\hline granodiorite Kornynsky & 0.17 & 1.90 & 2707 & - & - & - & 7.9 & - \\
\hline granite Korostyshevsky & 0.36 & 2.30 & 2644 & 2.56 & 0.17 & 6.3 & 3.5 & 2.6 \\
\hline granite Zhytomyr & 0.22 & 0.87 & 2658 & 2.77 & 0.06 & 7.3 & 4.8 & 2.9 \\
\hline granite Kurchytsky, & 0.30 & 1.59 & 2661 & 3.02 & 0.16 & 7.0 & 4.2 & 2.8 \\
\hline granite Kamianobrodsky & 0.23 & 1.46 & 2653 & 3.22 & 0.21 & 7.3 & 4.8 & 2.9 \\
\hline Granodiorite Olexandrivsky & 0.25 & 1.70 & 2699 & 3.00 & - & 8.5 & 4.8 & 3.2 \\
\hline
\end{tabular}

The basis for assessing the petrophysical properties of rocks as the formation for radioactive waste disposal is the substantiation of the numerical values of the signs of suitability and selection of the reference petrotype, according to these features. This allowed us to classify all the petrotypes into conditionally suitable and conditionally unsuitable ones relatively to the reference petrotype. 
The analysis of the suitability of the key petrotypes by a particular petrophysical feature does not seem expedient, since the characterization of permeability as the main property of a crystalline rock in the context of creating safe RW repository is of complex character. In order to simplify the consideration of petrophysical properties, they were divided into groups: permeability properties (general and open porosity), density properties (mineral and volume density), thermal properties (thermal conductivity, coefficient of thermal inhomogeneity), magnetic properties (magnetic susceptibility, natural magnetization intensity, Kenigsberg factor).

\subsubsection{Group of properties characterizing permeability}

Porosity and permeability are important physical characteristics of rocks when choosing a suitable geological formation for the disposal of radioactive waste. The void through which the aqueous solutions can migrate also affects the strength of rocks. Thus, rocks of different mineral content can have the same values of strength due to different values of porosity and permeability. It was established that permeability increases with increasing porosity. However, for different types of rocks, permeability for the same porosity is different. At equal porosity, the more homogeneous rocks will be characterized by minimum permeability, and rocks with relatively large and equal in size pores - by maximum permeability [5].

\subsubsection{Group of density properties}

The main factors determining the rock density are the mineral and chemical composition of the main rock-forming minerals, structural and textural features of rocks, their degree of diagenesis and metamorphism. In addition, the density of rocks is associated with their position in different tectonic structures, with the age of their formation, regional and local changes in area and in vertical. The density of the igneous rocks depends mainly on the rock composition and grows with increasing their basicity. Porosity has a noticeable effect on density: relatively low density values are proved by increased values of porosity.

\subsubsection{A group of thermal properties}

At the time of RW disposal, the release of radiogenic heat will continue. Accordingly, rocks should have sufficient heat conductivity and heat capacity, which will promote its scattering in the environment. An example of petrotypes of the Volyn megablock was the analysis of the dependence of heat conductivity on the mineral composition and grain size, total and open porosity. In particular, the high content of quartz and $\mathrm{SiO}_{2}$ corresponds to a higher value of thermal conductivity. Dependence of the latter on the size of the minerals' grains has directly proportional character: with decreasing grain size, the thermal conductivity decreases. It also has an uneven character with respect to the rock sample, as evidenced by the coefficient of thermal inhomogeneity: its increase leads to a decrease in thermal conductivity and serves as evidence of secondary changes in the rock (metasomatism, development of fragile deformations, etc.). Thermal conductivity increase leads to a change in the volume of the rock, and this, in turn, leads to a change in strength characteristics. So, with porosity increasing thermal conductivity decreases. The optimal solution when selecting the suitable rocks for radioactive waste disposal should be based on a comprehensive assessment of such characteristics. 


\subsubsection{Group of magnetic properties}

Magnetic characteristics do not directly affect the safety functions of the components of the geological formation. However, their study may provide additional information on the degree of iron oxidation and its preservation. The index of oxidation to a certain extent characterizes the depth of rocks formation, which was taken into account when performing a complex petrophysical assessment.

\subsubsection{Group of strength and elastic properties}

The safety of radioactive waste disposal depends to a large extent on the strength characteristics of rocks. They depend on the structure of the rock, its porosity, granularity, fracturing [6]. The fine-grained rock structure is characterized by better strength than medium- or coarse-grained structure. The porphyry structure usually increases the strength of the rocks, especially when the inclusions are insignificant and the bulk of rock is finecrystalline and monolithic. With increasing temperature (from room temperature to 200$280^{\circ} \mathrm{C}$ ), the strength characteristics increase due to increased strength of adhesion between minerals and reducing porosity. Because of low porosity, the magmatic rocks belong to the most elastic rocks.

To evaluate the elastic properties, we use indicators such as the Young's modulus E, Poisson ratio $v$, total compression modulus $\mathrm{K}$, shear modulus $\mathrm{G}$. The module of elasticity, shear and total compression increase sharply with increasing of rock density, which is higher at the low content of silicic acid, as its specific weight is negligible. The values of the Poisson ratio give indication of the approximate quartz content. Its presence in the rocks always leads to a decrease in the $v$ value. Granite is characterized by the highest compressibility among the igneous rocks. Consequently, the higher values of elasticity, compression and shear modules, the less their porosity and the greater density respectively, the rocks are characterized by greater strength.

\subsection{Selection of a reference petrotype}

The classification of the key petrotypes of the Volyn megablock by the degree of their relative suitability was performed aimed at the subsequent use for the disposal of radioactive waste. This classification was based on the analysis of informative properties (volume density, total and open porosity, thermal conductivity, grain size, etc.), which directly or indirectly determine the permeability of the rocks.

The relative degree of petrotype suitability can be determined by the proximity of its informative characteristics to the characteristics of a particular "reference" petrotype. "Reference" petrotype is a factitious rock whose properties were formed from the best indicators of investigated rock petrotypes most relevant to the requirements of the geological disposal safety. According to the characteristics of such a "reference" petrotype, all key petrotypes of the Volyn megablock were systematized.

Taking into account the volume of the whole sample for granitoid properties, in order to evaluate subsequent rocks selection the mode is taken as the main statistical characteristic of rocks.

Mode as one of the statistical characteristics of the sample, is an indicator of the most repetitive parameter and can be used to select the criterion signs of the reference petrotype. Estimation of the petrotype for each of the properties will be carried out in accordance with the "quality" of characteristic, and depending on its compliance with the acceptability the numerical value will be assumed being greater or lower than the mode for given petrophysical property under consideration. In the case of porosity, for example, the 
reference characteristic of this rock will consist of the values lower than or equal to the sample mode. Thus, the criterion values of the petrophysical characteristics were selected in accordance with the numerical value of the mode of each property.

Considering the volume density and the heat conductivity, the "suitable" petrotype by given feature can be petrotypes with a numerical value greater than the criterion (numerical value of the mode). In the case of general and open porosities petrotypes with a numerical value lower than the reference can be attributed to more suitable ones.

Thus, to determine the petrotype standard for granites of the Volynsky megablock, the petrophysical properties corresponding to the mode of sample for each property were chosen into the criterion values of the signs (taking into account the class according to the rock structure). The reference prototype signs are shown in Table 2.

Table 2. Signs of the reference petrotype.

\begin{tabular}{|c|c|c|c|c|c|c|c|c|}
\hline 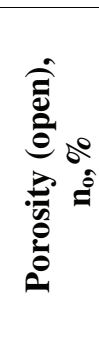 & 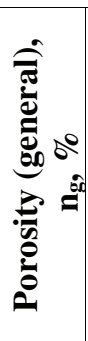 & 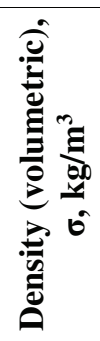 & 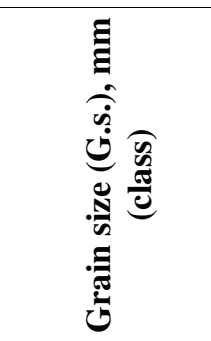 & 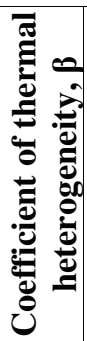 & 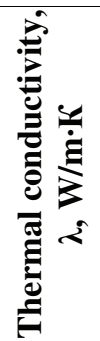 & 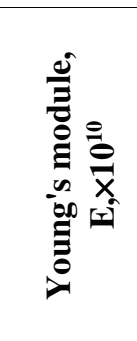 & 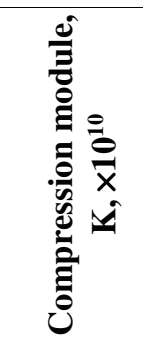 & 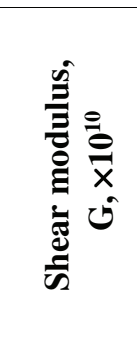 \\
\hline $\begin{array}{r}\text { less } \\
0.3\end{array}$ & $\begin{array}{r}\text { less } \\
2.0\end{array}$ & $\begin{array}{l}\text { more } \\
2630\end{array}$ & $\begin{array}{c}0^{-1}-2.5 \times 10 \\
\text { (2) }\end{array}$ & $\begin{array}{l}\text { less } \\
0.17\end{array}$ & $\begin{array}{c}\text { more } \\
3.1\end{array}$ & $\begin{array}{c}\text { more } \\
7.1 \times 10^{10}\end{array}$ & $\begin{array}{c}\text { more } \\
4.8 \times 10^{10}\end{array}$ & $\begin{array}{c}\text { more } \\
2.9 \times 10^{10}\end{array}$ \\
\hline
\end{tabular}

When analyzing the petrotypes of the Volyn megablock relative to reference petrotype, they are placed in a certain hierarchy by petrophysical properties. In order to further classify them by the degree of suitability, the "weighting" factor of petrophysical properties was taken into account when choosing a safe geological formation for radioactive waste disposal.

The values of weighting factor were determined according to the contribution to the safety of the disposal facility in the conditions of its placement in crystalline rocks. In particular, in these conditions, the highest coefficient is given to the index of rock characteristic that is most closely related to permeability. Thus, International Atomic Energy Agency (IAEA) recommendations were taken into account, according to which the information on the porous and fractured rock structure is important for ensuring the longterm performance of the repository system. The thermal and thermo-mechanical properties of rocks were taken into account as well.

After comparing each of the key petrotypes of the Volyn megablock with the reference, they will be characterized by the coincidence of a certain number of signs. The use of the transition coefficient allowed us to estimate the "weight" load of these characteristics and to determine the relative degree of the petrotypes suitability for the disposal of radioactive waste. Table 3 summarizes the significance of petrophysical characteristics and their compliance with safety requirements.

Table 4 shows the degree of proximity of the some key petrotypes of the Korostenkyi and Zhytomyr complexes to the reference petrotype, taking into account the weight coefficients of the characteristics used. According to Table 4, such petrotypes as Ignatpilskyi granite, Zhytomyr granite and Kamyanoborodskyi granite are close to the reference petrotype by the greatest number of signs.

Based on the results of petrophysical analysis of the key petrotypes for the Volyn megablock and taking into account the relative degrees of suitability of the petrotypes of those complexes that can be found within the CEZ and adjacent areas, the granitoids of the 
Korosten complex can be provisionally considered as the most promising. The granitoids of the Zhytomyr complex may also be suitable for further research.

Table 3. Petrophysical characteristics and their compliance with safety requirements.

\begin{tabular}{|c|c|c|}
\hline № & \multicolumn{2}{|l|}{ Characteristics and Value Coefficient / Reasoning } \\
\hline \multirow[t]{2}{*}{1} & Porosity (open), $\mathrm{n}_{\mathrm{o}}, \%$ & 3 \\
\hline & \multicolumn{2}{|l|}{ It is crucial for the migration of radionuclides } \\
\hline \multirow[t]{2}{*}{2} & Porosity (general), $\mathrm{n}_{\mathrm{g}}, \%$ & 2 \\
\hline & \multicolumn{2}{|c|}{ Significantly affects the processes of migration and fixation of radio nuclides } \\
\hline \multirow[t]{2}{*}{3} & Density (volumetric), $\sigma, \mathrm{kg} / \mathrm{m}^{3}$ & 2 \\
\hline & \multicolumn{2}{|c|}{$\begin{array}{l}\text { The size of the grains largely determines the strength and thermal characteristics of } \\
\text { the petrotype, as well as the potential predisposition of the brittle deformations, } \\
\text { which is directly related to safety requirements }\end{array}$} \\
\hline \multirow[t]{2}{*}{4} & Grain size (G.s.), mm (class) & 2 \\
\hline & \multicolumn{2}{|c|}{$\begin{array}{l}\text { Evidence of the presence of secondary rock transformations or the degree of their } \\
\text { heterogeneity, which is clearly undesirable from the standpoint of safety }\end{array}$} \\
\hline \multirow[t]{2}{*}{5} & Coefficient of thermal heterogeneity, $\beta$ & 1 \\
\hline & \multicolumn{2}{|c|}{$\begin{array}{l}\text { Although the sign is directly related to the safety requirements, the low thermal } \\
\text { conductivity of the enclosing rocks may be compensated by design decisions }\end{array}$} \\
\hline \multirow[t]{2}{*}{6} & Thermal conductivity, $\mathrm{W} / \mathrm{m} \cdot \mathrm{K}$ & 1 \\
\hline & \multicolumn{2}{|c|}{ Has a small range of variations and is indirectly related to security requirements } \\
\hline \multirow{2}{*}{$\begin{array}{l}7- \\
9\end{array}$} & Young's module E, Compression module K, Shear modulus G, Pa & 0,5 \\
\hline & \multicolumn{2}{|c|}{$\begin{array}{l}\text { Granites are quite strong rocks. The range of strength characteristics is negligible, } \\
\text { so these characteristics would have an impact on the results of the evaluation }\end{array}$} \\
\hline
\end{tabular}

Table 4. The degree of proximity of the some key petrotypes of the Korostenkyi and Zhytomyr complexes to the reference petrotype.

\begin{tabular}{|c|c|c|c|c|c|c|c|c|c|c|}
\hline Petrotypes & $\mathbf{n}_{\mathbf{0}} \%$ & $\mathbf{n}_{\mathrm{g}}, \%$ & $\begin{array}{l}\text { G.s., } \\
\text { mm }\end{array}$ & $\underset{3}{\sigma,}$ & $\begin{array}{c}\lambda \\
\mathbf{W} / \mathbf{M} \bullet \\
\mathbf{K}\end{array}$ & $\boldsymbol{\beta}$ & $\begin{array}{l}E, x \\
10^{10}\end{array}$ & $\begin{array}{l}K, X \\
10^{10}\end{array}$ & $\begin{array}{l}G, \times \\
10^{10}\end{array}$ & $\begin{array}{l}\text { The } \\
\text { tota } \\
\text { l } \\
\text { scor } \\
\text { e }\end{array}$ \\
\hline Reference & 3 & 2 & 2 & 1 & 1 & 2 & 0.5 & 0.5 & 0.5 & 12.5 \\
\hline \multicolumn{11}{|c|}{ Korostensky complex, granite, rapakivi-like granite } \\
\hline Ignatpilsky & 3 & 2 & 2 & - & - & 2 & 0.5 & 0.5 & - & 10 \\
\hline Rozsokhivsky & - & 2 & - & - & 1 & - & - & - & - & 3 \\
\hline Berezovsky & 3 & 2 & - & - & - & - & 0.5 & 0.5 & - & 6 \\
\hline Korostensky & - & 2 & - & - & - & 2 & - & - & - & 4 \\
\hline \multicolumn{11}{|c|}{ Zhytomyr complex, granite } \\
\hline Zhytomyr & 3 & 2 & - & 1 & - & 2 & 0.5 & 0.5 & 0.5 & 9.5 \\
\hline Kamianobrodsky & 3 & 2 & - & 1 & 1 & - & 0.5 & 0.5 & 0.5 & 8.5 \\
\hline Novoromanivsky & - & 2 & - & 1 & - & - & - & - & - & 3 \\
\hline
\end{tabular}

The petrophysical properties of granitoid of the Forsmark have been studied in sufficient detail $[7,8,9]$. The mean value of the porosity (open) for granite of the Forsmark is $0.5-0.55 \%$, density $-2642 \mathrm{~kg} / \mathrm{m}^{3}$, Poisson's ratio - 0.24 [7]. Pre-comparison these values with the values of the granitoids of the Volyn megablock (the mean value of the porosity (open) for granite is $0.34 \%$, density $-2645 \mathrm{~kg} / \mathrm{m}^{3}$, Poisson's ratio -0.23 ) show the similarity of the granitoids of the Volyn megablock to the granitoids of the Forsmark site in Sweden. But it requires a detailed description of data from Sweden. 
In the future, during prospecting and exploration works for siting of RW geological repository, the petrotypes studied may be prospective analogues and, respectively, search indicators of the host environment for development of the RW disposal system.

\section{Conclusions}

The paper is devoted to studying the permeability of Volyn region's granitoids with analyzing their petrophysical properties, some petrographical characteristics with the view to choosing the least permeable and so the most suitable geological formation for the RW disposal.

On a basis of the petrophysical estimations of the granitoids properties the argumentation of permeability has been developed for the petrotypes of Volyn region's as a geological formation for RW disposal has been treated. On a basis of the integrated petrophysical, structural and textural estimations of the granitoid's properties the method of the classification of the petrotypes with their relative rate of suitability for RW disposal.

The classification of petrotypes and typification of the granitoids has a perspective for further researches of these granitoids as host rock of radioactive waste disposal. As a result of studying the perspectives were shown of the Ignatpilskyi and Zhytomyr petrotype of the Korostenskyi and Zhytomyr complexes of the granitoids as host rock for the RW disposal.

The final proof of the suitability of the studied granitoids can only be obtained by the results of prospecting and exploration works in the course of safety analysis of the geological disposal system. The results obtained should be taken into account when planning and performing prospecting and exploration works that will be conducted for siting of geological repository of radioactive waste.

\section{References}

1. National target program for radioactive waste management http://zakon5.rada.gov.ua/laws/show/516-17

2. On approval of the strategy for radioactive waste management in Ukraine http://zakon3.rada.gov.ua/laws/show/990-2009-\%D1\%80

3. T. McEwen, T. Aikas, The site selection process for a spent fuel repository in Finland, - summary report (Posiva OY, Finland, 2000)

4. M.I. Tolstoy, Yu.L. Hasanov, N.V. Kostenko, A.P. Gozhyk, O.V. Shabatura, Petrochemistry and petrophysics of Ukrainian shield granitoids (K. Kyiv University, 2003)

5. N.B. Dortman, Rocks and minerals (M. Nedra, V.1, 1992)

6. V.V. Rzhevsky, G.Ya. Novik, Fundamentals of rock physics (M. Nedra, 1964)

7. H. Isaksson, H. Mattsson, H. Thunehed, M. Keisu, Interpretation of petrophysical surface data. Stage 1 (2002). Forsmark site investigation. (Report P-03-102, 2004) http://www.skb.com/publication/21314/P-03-102webb.pdf

8. J. Petersson, J. Berglund, P. Danielsson, A. Wängnerud, E.-L. Tullborg, H. Mattsson, H. Thunehed, H. Isaksson, H. Lindroos, Petrography, geochemistry, petrophysics and fracture mineralogy of boreholes KFM01A, KFM02A and KFM03A+B. Forsmark site investigation (Report P-04-103, 2004) http://www.skb.com/publication/22226/P-04103webb.pdf

9. K. Tiensuu, E. Heikkinen, KBS-3H. Geophysical logging of borehole K08028F01 (Report P-15-15, 2016) http://www.skb.com/publication/2487738/P-15-15.pdf 